$\begin{array}{ll}\text { Research Square } & \text { Preprints are preliminary reports that have not undergone peer review. } \\ \text { They should not be considered conclusive, used to inform clinical practice, } \\ \text { or referenced by the media as validated information. }\end{array}$

\title{
Fatigue is associated with physical inactivity in people with multiple sclerosis despite different environmental backgrounds: merging and comparing cohorts from Turkey and Israel
}

\section{Asiye Tuba Ozdagar}

Graduate School of Health Sciences, Dokuz Eylül University, Izmir, Turkey https://orcid.org/0000-0003-0043-9374

\section{Turhan Kahraman}

Department of Physiotherapy and Rehabilitation, Faculty of Health Sciences, Izmir Katip Celebi University, Izmir, Turkey https://orcid.org/0000-0002-87760664

\section{Serkan Ozakbas}

Department of Neurology, Faculty of Medicine, Dokuz Eylül University, Izmir, Turkey https://orcid.org/0000-0003-2140-4103

\section{Anat Achiron}

Sackler Faculty of Medicine, Tel-Aviv University, Israel; Sagol School of Neuroscience, Tel-Aviv University, Tel-Aviv, Israel; Multiple Sclerosis Center, Sheba Medical Center, Tel Hashomer, Israel https://orcid.org/0000-0002-2020-3126

Alon Kalron ( $\square$ alkalron@gmail.com )

Department of Physical Therapy, School of Health Professions, Sackler Faculty of Medicine Tel-Aviv University, Israel https://orcid.org/0000-0001-79990868

\section{Research Article}

Keywords: Multiple sclerosis, Physical activity, Fatigue, Disease related symptoms

Posted Date: August 24th, 2021

DOI: https://doi.org/10.21203/rs.3.rs-841629/v1

License: @ (i) This work is licensed under a Creative Commons Attribution 4.0 International License. Read Full License

Version of Record: A version of this preprint was published at Multiple Sclerosis and Related Disorders on December 1st, 2021. See the published version at https://doi.org/10.1016/j.msard.2021.103456. 


\section{Abstract}

Background Examining physical activity in people with multiple sclerosis (PwMS) from different environmental backgrounds might increase understanding and awareness of inactivity in PwMS.

Objectives To compare the level of physical activity in PwMS in Israel and Turkey and to examine the relationship between the level of physical activity with common disease-related symptoms and demographical characteristics of PwMS.

Methods Cross-sectional data collected by two centers were combined. The physical activity level was determined by the Godin Leisure-Time Exercise Questionnaire, and subsequently, classified into one of three subgroups: "active", "moderately active" and "insufficiently active". Logistic regressions determined the risks of insufficiently active PWMS, according to age, gender, body mass index, disability, impact of walking impairment, disease duration, type of MS and perceived fatigue. The analysis of variance test determined the differences between countries in terms of outcome variables.

Results The study comprised 458 patients from Israel and 575 from Turkey; 68.2\% Turkish PwMS were classified as insufficiently active compared with $52.0 \%$ of Israeli PwMS. The percentage of insufficiently active PwMS was significantly higher in those categorized as fatigued compared to non-fatigued in the total cohort $(72.4 \%$ vs. $51.9 \%, p<0.001)$ and in each country separately. Based on the regression analysis, fatigue was the main factor associated with the insufficiently physically active group; odds ratio= 1.968 .

Interpretation PwMS with increased fatigue tend to be physically inactive compared with the non-fatigued. This observation is supported by the merged data collected from two countries, Turkey and Israel, representing PwMS from different environmental backgrounds.

\section{Introduction}

Multiple sclerosis (MS) is a demyelinating disease of the central nervous system (CNS) [1] with an estimated 2.8 million persons afflicted globally [2, 3]. The disease process produces a diversity of neuropathological changes in the CNS $[1,4]$ typically affecting a wide range of neurological functions including mobility, cognition, vision, muscle strength, endurance, coordination, and sensation. There is a consensus amongst clinicians that physical activity is imperative for people with MS (PwMS). Emerging evidence has demonstrated that physical activity can improve walking performance, balance, cognition, fatigue, depression and the quality of life of PwMS [5]. Furthermore, Barry et al [6] demonstrated that physical activity and exercise are potential immunomodulatory therapies targeting innate signaling mechanisms, and modulating MS symptom development and progression. Nonetheless, regardless of the benefits, up to $78 \%$ of PwMS do not participate in any meaningful physical activity [7]. Interestingly, the number of inactive PwMS contrasts with the fact that most PwMS believe that their health and function would improve if they would participate in physical activities [8].

The prevalence of physical inactivity in the general population varies between countries, even within countries of the same region. According to a pooled analysis of population-based surveys across 168 countries, the prevalence of people classified as physically inactive ranges from 5 to $67 \%$ [9]. Althoff et al [10] assessing physical activity via movement sensors, found disparities in physical activity participation between countries. The relatively large disproportions are explained by dissimilarities in environmental backgrounds including policies/guidelines of physical activity recommendations for adults between countries.

Only sparse data exist relating to the physical activity participation of PwMS from different environmental backgrounds. Reily et al [11] examined the prevalence of various comorbidities and modifiable lifestyle factors in PwMS, including the level of physical activity performed in different global regions (Australia, Europe, and North America). The authors found a strong inverse relationship between the level of physical inactivity and the physical aspects of quality of life in the total cohort. They also observed that the distribution of physical activity levels varied between regions. Whereas, $29.9 \%$ of PwMS were classified at a high physical activity level in North America, only $22.2 \%$ were classified at that level in Europe [11].

Examining physical activity in PwMS across different countries from different environmental backgrounds could be beneficial. Firstly, by examining PwMS from different environmental backgrounds can help clarify the precise impact of disease-related factors as barriers of inactivity in PwMS. Secondly, in the event of significant differences in physical activity, health professionals from one country might offer (or ask) guidance/advice from health professionals from another country. In the current study, we merged two relatively large cohorts from Turkey and Israel $(n=1033)$. This decision was made since both countries are located in the same global region; characterize patients with different environmental backgrounds (organizational and social) and use similar measurement tools for assessing common MS disease symptoms.

Therefore, the study objective was twofold: (1) to compare the level of physical activity in PwMS in Israel and Turkey (specifically, Izmir) representing PwMS from different environmental backgrounds; (2) to examine the relationship between the level of physical activity with common disease-related symptoms and demographical characteristics of PwMS in the total cohort and in each country separately.

\section{Materials And Methods}

\section{Study design and participants}

Cross-sectional data collected by two centers were merged. All data were collected in accordance with the International Declaration of Helsinki. Institutional Ethics Committees in both countries approved the separate protocols (GOA-2959 (Turkey); SMC-5596 (Israel)). Written informed consent was obtained from the Turkish participants. The Sheba Institutional Review Board Ethics Committee approved the extraction of demographic, clinical, and physical activity data for analysis in addition to a full exemption from written or verbal consent from the study participants. Hence, individual data will not be made available in 
order to protect the participants' identity. Each patient's record was referenced by an anonymous code number to ensure confidentiality during the statistical analyses.

The cross-sectional bi-center study comprised 1033 PwMS (40.1 \pm 12.3 years old, $65.0 \%$ female); 458 participants from the Multiple Sclerosis Center, Sheba Medical Center, Tel-Hashomer, Israel and 575 participants recruited from the Multiple Sclerosis Unit, Dokuz Eylul University Hospital, Izmir, Turkey. Both samples used standardized criteria for an MS diagnosis [12]. Participants were $>18$ years old. There were no restrictions for MS subtypes. Disease severity was measured in both centers by the Expanded Disability Status Scale (EDSS) [13]. The EDSS score for inclusion was defined at $\leq 6.5$, equivalent to walking $\sim 20 \mathrm{~m}$ with bilateral support. Common exclusion criteria were: relapse free for 90 days prior to the examination and an inability to understand and complete the patient-reported outcome measures due to linguistic, cognitive or other reasons.

\section{Outcome variables}

\section{Godin Leisure-Time Exercise Questionnaire (GLTEQ)}

The GLTEQ, a self-administered measuring tool for assessing physical activity [14] has been validated for use in PwMS [15]. This tool contains three items which measure the frequency of strenuous (i.e., jogging), moderate (i.e., fast walking) and mild (i.e., easy walking) exercise for periods of $>15$ minutes during one's free time throughout a typical week. The weekly frequencies occurring over a 7-day period of strenuous, moderate, and mild activities are multiplied by 9 , 5 , and 3 metabolic equivalents, respectively, and summed to form a measure of total leisure activity. The GLTEQ is an appropriate, simple, and effective tool for measuring the change in physical activity in response to an intervention in the MS population [16].

\section{2-item Multiple Sclerosis Walking Scale (MSWS-12)}

The MSWS-12, a valid questionnaire assessing walking ability in PWMS, is the most widely used patient-reported measure of perceived limitation in walking attributable to MS. Many studies recommend the use of the MSWS-12 due to its psychometric properties [17-19]. Each of the 12 items are rated on a scale of 1 (not at all) to 5 (extremely). Items cover different aspects of walking function and quality such as the ability to walk, walking speed, ability to run, ability to climb and descend stairs, ability to stand, balance, endurance, smoothness of gait, need for support (in and outdoors), effort and concentration required.

\section{Modified Fatigue Impact Scale (MFIS)}

The MFIS [20], a self-reported, multidimensional 21-item questionnaire, determined the level of perceived fatigue in the PwMS study group. This instrument captured information relating to the effects of fatigue within the physical (9 items), psychosocial ( 2 items), and cognitive (10 items) domains over a four-week period. Participants rated the 21 items on a 5-point Likert-type scale from never (0) to always (4). The MFIS yielded three subscale scores and an overall score ranging from 0 to 84 .

\section{Data analysis}

All data from each country were normally distributed according to the Kolmogorov-Smirnov test. Box plots determined outliers for each outcome. Data sets from each country were compared for heterogeneity by the Kruskal-Wallis Test. As for the level of physical activity, individuals from each data set were classified into one of three subgroups: "active", "moderately active" and "insufficiently active". Allocation was determined according to the GLTEQ. PwMS with scores $\geq 24$ units were classified as active, 14 to 23 were considered moderately active and those who scored $<14$ were classified as insufficiently active. The selected cut-off points were aligned with Godin's recommendations [21] and defined according to the literature [22]. Participants with disabilities were categorized as either "very mild" (EDSS 0-1.5), "mild" (EDSS 2.0-3.5), "moderate" (EDSS 4.0-5.5) or "severe" (EDSS 6.0-6.5). Perceived fatigue was categorized as "fatigued" (MFIS $\geq 38$ ) or "non-fatigued" (MFIS<38). The chi-square test determined the differences between countries in terms of MS type, gender distribution, physical activity level distribution, fatigue status and EDSS disability subgroups. Differences between countries in terms of age, disease duration, body mass index (BMI), EDSS, GLTEQ, MSWS-12 and MFIS were determined by the analysis of variance test. Univariate and multivariate logistic regression determined the risk of classification as insufficiently active according to age, gender, BMI, EDSS, MSWS-12, disease duration, type of MS and perceived fatigue categories. All analyses were performed using the SPSS software program (IBM SPSS Statistics for Windows, Version 27.0 Armonk, NY, USA: IBM Corp). All reported $P$ values were two-tailed. The level of significance was set at $P<0.05$.

\section{Results}

The total cohort's GLTEQ score was $13.3 \pm 17.7$. Significant differences in physical activity were observed between countries. Israeli PwMS participated in more leisure-time physical activities compared to the Turkish PwMS; GLTEQ $=16.4 \pm 18.4$ vs. $10.7 \pm 16.6 ; p<0.001$. Moreover, $68.2 \%$ of Turkish PwMS were classified as insufficiently active compared with $52.0 \%$ of the Israeli PwMS. For comparison, we present data on the percentage of people classified as insufficiently active in the general population published by the World Health Organization [9]. The mean percentage in the Middle East and eastern Europe regions is $32.8 \%$ and $23.4 \%$, respectively. The mean percentage in Turkey is $30.6 \%$. To the best of our knowledge, no data exists as to the percentage of people classified as insufficiently active in Israel, although, the percentage is considered in the same range as countries classified with middle-high incomes (between 26 and 36\%). Demographic and clinical characteristics of the study cohort are presented in Table 1.

Distribution of physical activity subgroups according to disability (EDSS), fatigue categories, MS type and gender are illustrated in Figs. 1-4. The percentage of the insufficiently active group was higher in Turkish PwMS compared to the Israeli PwMS for all disability levels, with the exception of severely disabled, which was identical. Furthermore, the percentage of insufficiently active people was significantly higher in PwMS categorized as fatigued compared to non- 
fatigued in the total cohort $(72.4 \%$ vs. $51.9 \%, \mathrm{p}<0.001)$ and in each country separately. A higher percentage of females were classified as insufficiently active compared with males in the total cohort, $63.7 \%$ vs. $55.6 \%$; $<<0.001$.

Based on the multivariate logistic regression analysis of the total sample, being female and fatigued were the main factors associated with the insufficiently physically active group; odds ratio $=1.364,1.968$, respectively. Moreover, fatigue was the single significant risk factor for physical inactivity in each country. Table 2 presents the logistic regression analysis evaluating factors associated with insufficiently physically active. Figure 5 illustrates the contribution of fatigue on physical inactivity in terms of odds ratio according to country and in the total cohort.

\section{Discussion}

The main findings of this research were the strong association between increased perceived fatigue with decreased participation in leisure time physical activities in PwMS. PWMS, categorized as fatigued, had a 2.5-times higher risk of becoming insufficiently physically active compared to the PwMS who were non-fatigued. Importantly, a novelty of our study was the analyses of merged data from two relatively large samples collected from different environmental backgrounds. Although, several systematic reviews have investigated this topic, to the best of our knowledge, this is the first study comparing physical activity behavior in PWMS according to country of origin. We decided to focus specifically on Israel and Turkey as these two countries represent PwMS from the same global region but with different environmental backgrounds. In this context, it is worth mentioning a recent study exploring expert views on facilitators and barriers on long-term physical activity among PwMS [25]. The authors divided potential factors into two major categories: environmental and personal. Environmental factors included organizational aspects, e.g availability, access and quality of physical activity options, health system services, health professionals, financial resources, social and peer support. Personal factors related to the individual, i.e., age, gender, disease related factors, motivation, skills, goals, exercise history, knowledge and outcome experiences/expectancies.

Our study does not capture all potential facilitators and barriers of physical activity participation in PwMS, however, we do add significant information relating to the contribution of common disease-related factors on inactivity in PWMS. Regardless of the different environmental backgrounds, together with different rates of physical activity participation between the two cohorts, we found that perceived fatigue was a major contributor of inactivity in both cohorts of PwMS. Worth noting, disability (represented by the EDSS), BMI, type of MS, disease duration and subjective impact of the disease on mobility (represented by the MSWS-12) were not significant factors for inactivity according to the multivariate logistic regression. Interestingly, our finding regarding the MSWS-12 indicates that when the goal is to encourage physical activity in PWMS, more effort should be invested in the aspect of reducing fatigue versus improving mobility.

The significant inversed relationship between perceived fatigue and participation in physical activity which was demonstrated in our study is in agreement with the MS literature [24-27]. Perceived fatigue has been found to decrease the likelihood of engaging in physical activity [28, 29]. Due to the current study's design, we could not draw firm conclusions as to the cause-effect relationship between fatigue and physical activity, therefore, we reference several previous studies which may lend an insight into this complex relationship. Smith et al [29] investigated how fatigue influences community exercise participation in PwMS by collecting information via a face-to face personal interview. Specifically, the authors focused on how PwMS managed to engage in community exercise despite their fatigue. They also reported that what characterized PwMS who were able to maintain exercising, was the ability to readjust goalorientated behaviors on a continual basis. It is believed that the ability to adjust the PWMS' goals is linked to the levels of self-efficacy and should, therefore, be considered when encouraging PwMS to engage in meaningful exercise. Motl et al [30] found an association between increased fatigue, physical inactivity, and low self-efficacy. The authors investigated the intermediary role of disability, fatigue, mood, and self-efficacy between physical activity and quality of life in PwMS. In the present study, data were not collected relating to mood or self-efficacy. Nevertheless, we reinforced the existing knowledge by demonstrating that elevated fatigue is related to less participation in leisure time physical activities in PwMS, regardless of country (Israel and Turkey), health system or national physical activity guidelines.

The relationship between physical activity and fatigue has been observed in various clinical trials reporting on the efficacy of exercise programs on fatigue in PWMS. According to Andreasen et al's systematic review [31], physical activity and exercise training have the potential to generate a positive effect on PwMS fatigue. Turner et al [32] examined the efficacy of a telephone-based physical activity counselling intervention of 64 PwMS and found that participants in the intervention group significantly reduced perceived fatigue and depression upon termination of the program. In another randomized controlled trial, a significant reduction in fatigue was recorded following a 6-month behavioral intervention targeting lifestyle physical activity in 82 PwMS [33].

Despite the focus of our discussion on the impact of disease-related factors, specifically fatigue on inactivity in PwMS, we find it important to mention other factors as well. A complex range of factors in the micro and macro environments influence the likelihood that an individual will be physically active. Factors in the macro environment include general socio economic, cultural, and environmental conditions, i.e., participation in leisure-time physical activity tend to be directly related to socioeconomic status [34]. Additionally, cultural background may affect the choice of leisure-time activities. Communities can strongly influence people's levels of physical activity, particularly through social support systems [35]. According to a Eurobarometer survey, disparities exist throughout the European Union as to the extent to which people are acquainted with activity in their local areas [36]. Based on the present comparison between Israeli PwMS and Turkish PwMS, we believe that besides common disease features, future research studies examining physical activity in PwMS should consider macro environment factors.

Our study has many strengths such as the large, pooled sample of PwMS, however, there were several limitations which warrant attention. Firstly, physical activity was quantified solely by a self-reported questionnaire. Other tools such as accelerometers and pedometers are equally appropriate in measuring physical activity, although, they also have their limitations [37]. In this context, it is worth noting that in a recent validation study of the GLTEQ in PwMS, the scores primarily reflected moderate-to-vigorous physical activity rather than light-physical activity and sedentary behavior [38]. Secondly, the level of fatigue was solely estimated from data taken from the MFIS questionnaire without analyzing the test's subcategories, although, it is questionable whether additional 
fatigue measures would have led to different conclusions. Finally, our data did not include all potential factors related with long-term physical activity adherence in PwMS, as we merged only data that was collected at both MS centers.

In conclusion, participation in leisure-time physical activity is related to fatigue in PwMS. PwMS with increased fatigue tend to be physically inactive compared with the non-fatigued. This observation is supported by the merged data collected from two countries, Turkey and Israel, representing PwMS from different environmental backgrounds. Additional personal and environmental factors should be considered in future studies examining physical activity behavior in the PwMS population to further clarify this important topic.

\section{Declarations}

Author contributions ATO cconceptualized; formal analysis; writing - review and editing; visualization. TK: Writing-review and editing. SO Writing-review and editing; resources. AA writing-review and editing; resources.

AK: Conceptualized; writing-original draft preparation; visualization.

\section{Compliance with ethical standards}

Conflicts of interest The authors declare that they have no conflict of interest.

Ethical approval The Institutional Ethics Committees in both countries approved the separate study protocols (GOA-2959 (Turkey); SMC-5596 (Israel). Written informed consent was obtained from the Turkish participants. The Sheba Institutional Review Board Ethics Committee approved the extraction of demographic, clinical, and physical activity data for analysis in addition to a full exemption from written or verbal consent from the study participants. Hence, individual data will not be made available in order to protect the participants' identity. Each patient's record was referenced by an anonymous code number to ensure confidentiality during the statistical analyses.

\section{References}

1. Trapp BD, Nave K (2008) Multiple sclerosis: an immune or neurodegenerative disorder? Annu Rev Neurosci

31:247-369.

2. Mayr WT, Pittock SJ, McClelland RL, Jorgensen NW, Noseworthy JH, Rodriguez M (2003) Incidence and prevalence of multiple sclerosis in Olmstead County, Minnesota, 1985-2000. Neurology 61:1373-1377.

3. Wallin MT, Page WF, Kurtzke JF (2000) Epidemiology of multiple sclerosis in US veterans. VIII. Long term survival after onset of multiple sclerosis. Brain 123:1677-1687.

4. Hauser SL, Oksenberg JR (2006) The neurobiology of multiple sclerosis: genes, inflammation, and neurodegeneration. Neuron 52:61-76.

5. Motl RW, Sandroff BM (2015) Benefits of exercise training in multiple sclerosis. Curr Neurol Neurosci Rep15:62.

6. Barry A, Cronin O, Ryan AM, Sweeney B, Yap SM, O'Toole O, Allen AP, Clarke G, O'Halloran KD, Downer EJ (2016) Impact of exercise on innate immunity in multiple sclerosis progression and symptomatology. Front Physiol 7:194.

7. Beckerman H, de Groot V, Scholten MA, Kempen JC, Lankhorst GJ (2010) Physical activity behavior of people with multiple sclerosis: understanding how they can become more physically active. Phys Ther 90: 1001-1013.

8. Ferrier S, Dunlop N, Blanchard C (2010) The role of outcome expectations and self-efficacy in explaining physical activity behaviors of individuals with multiple sclerosis. Behav Med 36:7-11.

9. Guthold R, Stevens GA, Riley LM, Bull FC (2018) Worldwide trends in insufficient physical activity from 2001 to 2016: a pooled analysis of 358 population-based surveys with 1.9 million participants. Lancet Glob Health 6:e1077-e1086.

10. Althoff T, Sosič R, Hicks JL, King AC, Delp SL, Leskovec J (2017) Large-scale physical activity data reveal worldwide activity inequality. Nature 547:336339.

11. Reilly GD, Mahkawnghta AS, Jelinek PL, De Livera AM, Weiland TJ, Brown CR, Taylor KL, Neate SL, Jelinke GA, Marck CH (2017). International differences in multiple sclerosis health outcomes and associated factors in a cross-sectional survey. Front Neurol 8:229.

12. Thompson AJ, Banwell BL, Barkhof F, (2018). Diagnosis of multiple sclerosis: 2017 revisions of the McDonald criteria. Lancet Neurol17:162-173.

13. Kurtzke JF (1983) Rating neurologic impairment in multiple sclerosis: an expanded disability status scale (EDSS). Neurology 33:1444-1452.

14. Godin G, Shephard RJ (1985) A simple method to assess exercise behavior in the community. Can J Appl Sport Sci 10:141-146.

15. Gosney JL, Scott JA, Snook EM, Motl RW (2007) Physical activity and multiple sclerosis: validity of self-report and objective measures. Fam Commun Health;3:144-150. 
16. Sikes EM, Richardson EV, Cederberg KJ, Sasaki JE, Sandroff BM, Motl RW (2018) Use of the Godin leisure-time exercise questionnaire in multiple sclerosis research: a comprehensive narrative review. Disabil Rehabil 17 1-25.

17. Hobart JC, Riazi A, Lamping DL, Fitzpatrick R, Thompson AJ (2003) Measuring the impact of MS on walking ability: the 12-Item MS Walking Scale (MSWS-12). Neurology 60:31-36.

18. Baert I, Freeman J, Smedal T, et al (2014) Responsiveness and clinically meaningful improvement, according to disability level, of five walking measures after rehabilitation in multiple sclerosis: a European multicenter study. Neurorehabil Neural Repair 28:621-631.

19. Baert I, Smedal T, Kalron A, et al (2018) Responsiveness and meaningful improvement of mobility measures following MS rehabilitation. Neurology 91:e1880-e1892.

20. Kos D, Kerckhofs E, Carrea I, Verza R, Ramos M, Jansa J (2005) Evaluation of the Modified Fatigue Impact Scale in four different European countries. Mult Scler 11:76-80.

21. Godin G (2011) The Godin-Shephard leisure-time physical activity questionnaire. Health \& Fitness Journal of Canada 4:18-22.

22. Learmonth YC, Dlugonski D, Pilutti LA, Sandroff BM, Klaren R, Motl RW (2013) Psychometric properties of the Fatigue Severity Scale and the Modified Fatigue Impact Scale. J Neurol Sci 331:102-107.

23. Riemann-Lorenz K, Wienert J, Streber R, Motl RW, Coote S, Heesen C (2020) Long-term physical activity in people with multiple sclerosis: exploring expert views on facilitators and barriers. Disabil Rehabil 42:3059-3071.

24. Backus D (2016) Increasing physical activity and participation in people with multiple sclerosis: a review. Arch Phys Med Rehabil 97:S210-S217.

25. Learmonth YC, Motl RW (2016) Physical activity and exercise training in multiple sclerosis: a review and content analysis of qualitative research identifying perceived determinants and consequences. Disabil Rehabil 38:1227-1242.

26. Mayo CD, Miksche K, Attwell-Pope K, Gawryluk JR (2019) The relationship between physical activity and symptoms of fatigue, mood, and perceived cognitive impairment in adults with multiple sclerosis. J Clin Exp Neuropsychol 41:715-722.

27. Kalron A, Menascu S, Frid L, Aloni R, Achiron A (2020) Physical activity in mild multiple sclerosis: contribution of perceived fatigue, energy cost, and speed of walking. Disabil Rehabil 42:1240-1246.

28. Johnson SL (2008) The concept of fatigue in multiple sclerosis. J Neurosci Nurs 40:72-77.

29. Smith CM, Fitzgerald HJ, Whitehead L (2015) How fatigue influences exercise participation in men with multiple sclerosis. Qual Health Res 25:179-188.

30. Motl RW, McAuley E, Snook EM, Gliottoni RC (2009) Physical activity and quality of life in multiple sclerosis: intermediary roles of disability, fatigue, mood, pain, self-efficacy and social support. Psychol Health Med 14:111-124.

31. Andreasen AK, Stenager E, Dalgas U (2011) The effect of exercise therapy on fatigue in multiple sclerosis. Mult Scler 17:1041-1054.

32. Turner AP, Hartoonian N, Sloan AP, Benich M, Kivlahan DR, Hughes C, Hughes AJ, Haselkorn JK (2016) Improving fatigue and depression in individuals with multiple sclerosis using telephone-administered physical activity counseling. J Consult Clin Psychol 84:297-309.

33. Pilutti LA, Dlugonski D, Sandroff BM, Klaren R, Motl RW (2014) Randomized controlled trial of a behavioral intervention targeting symptoms and physical activity in multiple sclerosis. Mult Scler 20:594-601.

34. Popham F, Mitchell R (2007) Relation of employment status to socioeconomic position and physical activity types. Prev Med 45:182-188.

35. Milton K, Cavill N, Chalkley A, Foster C, Gomersall S, Hagstromer M, Kelly P, Kolbe-Alexander T, Mair J, McLaughlin M, Nobles J, Reece L, Shilton T, Smith BJ, Schipperijn J (2021) Eight investments that work for physical activity. J Phys Act Health 18:625-630.

36. Moreno-Llamas A, García-Mayor J, De la Cruz-Sánchez E (2020) Physical activity barriers according to social stratification in Europe. Int J Public Health 65:1477-1484.

37. Sallis JF (2010) Measuring physical activity: practical approaches for program evaluation in Native American communities. J Public Health Manag Pract 16:404-410.

38. Motl RW, Bollaert RE, Sandroff BM (2018) Validation of the Godin Leisure-Time Exercise Questionnaire classification coding system using accelerometry in multiple sclerosis. Rehabil Psychol 63:77-82.

\section{Tables}

Table 1. Demographic and clinical characteristics of the study cohort 


\begin{tabular}{|c|c|c|c|c|}
\hline Variable & $\begin{array}{l}\text { Total Sample } \\
(n=1033)\end{array}$ & $\begin{array}{l}\text { Turkey } \\
(n=575)\end{array}$ & $\begin{array}{l}\text { Israel } \\
(n=458)\end{array}$ & $P$ value \\
\hline GLTEQ (score) & $13.29(17.7)$ & $10.7(16.6)$ & $16.4(18.4)$ & $<0.001$ \\
\hline \multicolumn{5}{|c|}{ Classification of physical activity level } \\
\hline Insufficiently active (n, \%) & $615(60.8)$ & $377(68.2)$ & $238(52.0)$ & \multirow[t]{3}{*}{$<0.001$} \\
\hline Moderately active (n, \%) & $182(18.0)$ & $76(13.7)$ & $106(23.1)$ & \\
\hline Active (n, \%) & $214(20.7)$ & $100(18.1)$ & $114(24.9)$ & \\
\hline Age (years) & $40.1(12.3)$ & $38.7(11.7)$ & $41.8(12.8)$ & $<0.001$ \\
\hline \multicolumn{5}{|l|}{ Gender } \\
\hline Female (n, \%) & $671(65.0)$ & $395(68.7)$ & $276(60.3)$ & \multirow[t]{2}{*}{0.005} \\
\hline Male $(n, \%)$ & $362(35.0)$ & $180(31.3)$ & $182(39.7)$ & \\
\hline Disease duration (years) & $8.4(8.4)$ & $9.4(8.0)$ & $7.1(8.6)$ & $<0.001$ \\
\hline $\mathrm{BMI}\left(\mathrm{kg} / \mathrm{m}^{2}\right)$ & $24.7(4.6)$ & $24.8(4.6)$ & $24.5(4.6)$ & 0.115 \\
\hline EDSS (median score/range) & $2.0(0-6.5)$ & $2.0(0-6.5)$ & $2.0(0-6.5)$ & 0.279 \\
\hline \multicolumn{5}{|l|}{ Classification of disability level } \\
\hline Very mild (0-1.5) (n, \%) & $424(41.0)$ & $268(46.6)$ & $156(34.1)$ & \multirow[t]{4}{*}{$<0.001$} \\
\hline Mild (2.0-3.5) (n, \%) & $301(29.1)$ & $136(23.7)$ & $165(36.0)$ & \\
\hline Moderate (4.0-5.5) $(n, \%)$ & $157(15.2)$ & $62(10.8)$ & $95(20.7)$ & \\
\hline Severe (6.0-6.5) (n, \%) & $151(14.6)$ & $109(19.0)$ & $42(9.2)$ & \\
\hline \multicolumn{5}{|l|}{ Type of MS } \\
\hline $\operatorname{RR}(n, \%)$ & $774(81.0)$ & $453(78.8)$ & $321(84.5)$ & \multirow[t]{2}{*}{0.028} \\
\hline Progressive (n, \%) & $181(19.0)$ & $122(21.2)$ & $59(15.5)$ & \\
\hline Perceived fatigue (MFIS score) & $31.9(21.9)$ & $30.6(22.2)$ & $33.6(21.4)$ & 0.026 \\
\hline Fatigue (n, \%) & $394(39.8)$ & $212(37.7)$ & $182(42.6)$ & \multirow[t]{2}{*}{0.114} \\
\hline Non-fatigue (n, \%) & $596(60.2)$ & $351(62.3)$ & $245(57.4)$ & \\
\hline MSWS-12 (\% score) & $35.0(33.0)$ & $32.4(33.3)$ & $38.5(32.5)$ & 0.003 \\
\hline \multicolumn{5}{|c|}{ Significant $\mathrm{p}$ values are presented in bold. } \\
\hline \multicolumn{5}{|c|}{ Values are presented as mean (SD) unless specified. } \\
\hline \multicolumn{5}{|c|}{ Number of missing data; GLTEQ $(n=22)$, Disease Duration $(n=52)$, BMI $(n=36)$, Type of MS $(n=78)$, Perceived Fatigue $(n=43)$, MSWS-12 (37). } \\
\hline \multicolumn{5}{|c|}{$\begin{array}{l}\text { GLTEQ, Godin Leisure-Time Exercise Questionnaire; PA, Physical Activity; BMI, Body Mass Index; EDSS, Expanded Disability Status Scale; RR, Relapsing } \\
\text { Remitting; MFIS, Modified Fatigue Impact Scale; MSWS-12, Multiple Sclerosis Walking Scale-12. }\end{array}$} \\
\hline
\end{tabular}


Table 2. Logistic regression analysis of factors associated with being insufficiently active

\begin{tabular}{|c|c|c|c|c|c|c|c|c|c|c|c|c|c|c|c|c|}
\hline & \multicolumn{6}{|c|}{ Total Sample } & \multicolumn{6}{|c|}{ Turkey } & \multicolumn{4}{|l|}{ Israel } \\
\hline & \multicolumn{6}{|c|}{ Insufficiently Active } & \multicolumn{6}{|c|}{ Insufficiently Active } & \multicolumn{4}{|c|}{ Insufficiently Active } \\
\hline & \multicolumn{3}{|c|}{ Univariate } & \multicolumn{3}{|c|}{ Multivariate } & \multicolumn{3}{|c|}{ Univariate } & \multicolumn{3}{|c|}{ Multivariate } & \multicolumn{3}{|c|}{ Univariate } & \\
\hline & OR & $\begin{array}{l}95.0 \% \\
\mathrm{Cl}\end{array}$ & $\begin{array}{l}\mathrm{P} \\
\text { value }\end{array}$ & OR & $\begin{array}{l}95.0 \% \\
\mathrm{Cl}\end{array}$ & $\begin{array}{l}\mathrm{P} \\
\text { value }\end{array}$ & OR & $\begin{array}{l}95.0 \% \\
\mathrm{Cl}\end{array}$ & $\begin{array}{l}\mathrm{P} \\
\text { value }\end{array}$ & OR & $\begin{array}{l}95.0 \% \\
\mathrm{Cl}\end{array}$ & $\begin{array}{l}\mathrm{P} \\
\text { value }\end{array}$ & OR & $\begin{array}{l}95.0 \% \\
\mathrm{Cl}\end{array}$ & $\begin{array}{l}\mathrm{P} \\
\text { value }\end{array}$ & 1 \\
\hline Age & 1.001 & $\begin{array}{l}0.991- \\
1.012\end{array}$ & 0.794 & 0.981 & $\begin{array}{l}0.967- \\
0.996\end{array}$ & 0.011 & 1.003 & $\begin{array}{l}0.987- \\
1.018\end{array}$ & 0.747 & 0.995 & $\begin{array}{l}0.974- \\
1.016\end{array}$ & 0.627 & 1.007 & $\begin{array}{l}0.993- \\
1.022\end{array}$ & 0.322 & 1 \\
\hline $\begin{array}{l}\text { Gender } \\
\text { (Female) }\end{array}$ & 1.398 & $\begin{array}{l}1.075- \\
1.818\end{array}$ & 0.012 & 1.364 & $\begin{array}{l}1.012- \\
1.838\end{array}$ & 0.041 & 0.748 & $\begin{array}{l}0.512- \\
1.094\end{array}$ & 0.135 & 1.360 & $\begin{array}{l}0.912- \\
2.027\end{array}$ & 0.132 & 0.758 & $\begin{array}{l}0.521- \\
1.103\end{array}$ & 0.148 & \\
\hline BMI & 1.021 & $\begin{array}{l}0.992- \\
1.050\end{array}$ & 0.156 & 1.020 & $\begin{array}{l}0.989- \\
1.053\end{array}$ & 0.211 & 1.025 & $\begin{array}{l}0.984- \\
1.066\end{array}$ & 0.233 & 1.028 & $\begin{array}{l}0.984- \\
1.073\end{array}$ & 0.214 & 1.102 & $\begin{array}{l}0.972- \\
1.054\end{array}$ & 0.563 & 1 \\
\hline EDSS & 1.092 & $\begin{array}{l}1.026- \\
1.163\end{array}$ & 0.006 & 1.003 & $\begin{array}{l}0.891- \\
1.129\end{array}$ & 0.964 & 1.040 & $\begin{array}{l}0.958- \\
1.129\end{array}$ & 0.344 & 0.905 & $\begin{array}{l}0.763- \\
1.075\end{array}$ & 0.255 & 1.186 & $\begin{array}{l}1.071- \\
1.314\end{array}$ & 0.001 & \\
\hline $\begin{array}{l}\text { Disease } \\
\text { duration }\end{array}$ & 1.016 & $\begin{array}{l}1.000- \\
1.033\end{array}$ & 0.049 & 1.020 & $\begin{array}{l}0.998- \\
1.041\end{array}$ & 0.074 & 1.003 & $\begin{array}{l}0.980- \\
1.026\end{array}$ & 0.814 & 0.996 & $\begin{array}{l}0.966- \\
1.028\end{array}$ & 0.825 & 1.019 & $\begin{array}{l}0.996- \\
1.043\end{array}$ & 0.104 & \\
\hline $\begin{array}{l}\text { Type of } \\
\text { MS (RR) }\end{array}$ & 0.887 & $\begin{array}{l}0.632- \\
1.244\end{array}$ & 0.488 & 1.080 & $\begin{array}{l}0.665- \\
1.755\end{array}$ & 0.756 & 0.752 & $\begin{array}{l}0.478- \\
1.182\end{array}$ & 0.217 & 0.640 & $\begin{array}{l}0.291- \\
1.405\end{array}$ & 0.266 & 1.359 & $\begin{array}{l}0.778- \\
2.376\end{array}$ & 0.281 & \\
\hline Fatigued & 2.431 & $\begin{array}{l}1.847- \\
3.199\end{array}$ & $<0.001$ & 1.968 & $\begin{array}{l}1.387- \\
2.794\end{array}$ & $<0.001$ & 2.245 & $\begin{array}{l}1.512- \\
3.335\end{array}$ & $<0.001$ & 2.019 & $\begin{array}{l}1.270- \\
3.211\end{array}$ & 0.003 & 3.087 & $\begin{array}{l}2.070- \\
4.605\end{array}$ & $<0.001$ & \\
\hline $\begin{array}{l}\text { MSWS- } \\
12\end{array}$ & 1.010 & $\begin{array}{l}1.006- \\
1.014\end{array}$ & $<0.001$ & 1.004 & $\begin{array}{l}0.997- \\
1.011\end{array}$ & 0.259 & 1.008 & $\begin{array}{l}1.002- \\
1.013\end{array}$ & 0.008 & 1.005 & $\begin{array}{l}0.995- \\
1.015\end{array}$ & 0.348 & 1.016 & $\begin{array}{l}1.010- \\
1.023\end{array}$ & $<0.001$ & \\
\hline
\end{tabular}

Significant $\mathrm{p}$ values are presented in bold.

BMI, Body Mass Index; EDSS, Expanded Disability Status Scale; RR, Relapsing Remitting; MFIS, Modified Fatigue Impact Scale; MSWS-12, Multiple Sclerosis I Confidence Interval; OR, Odds Ratio.

\section{Figures}




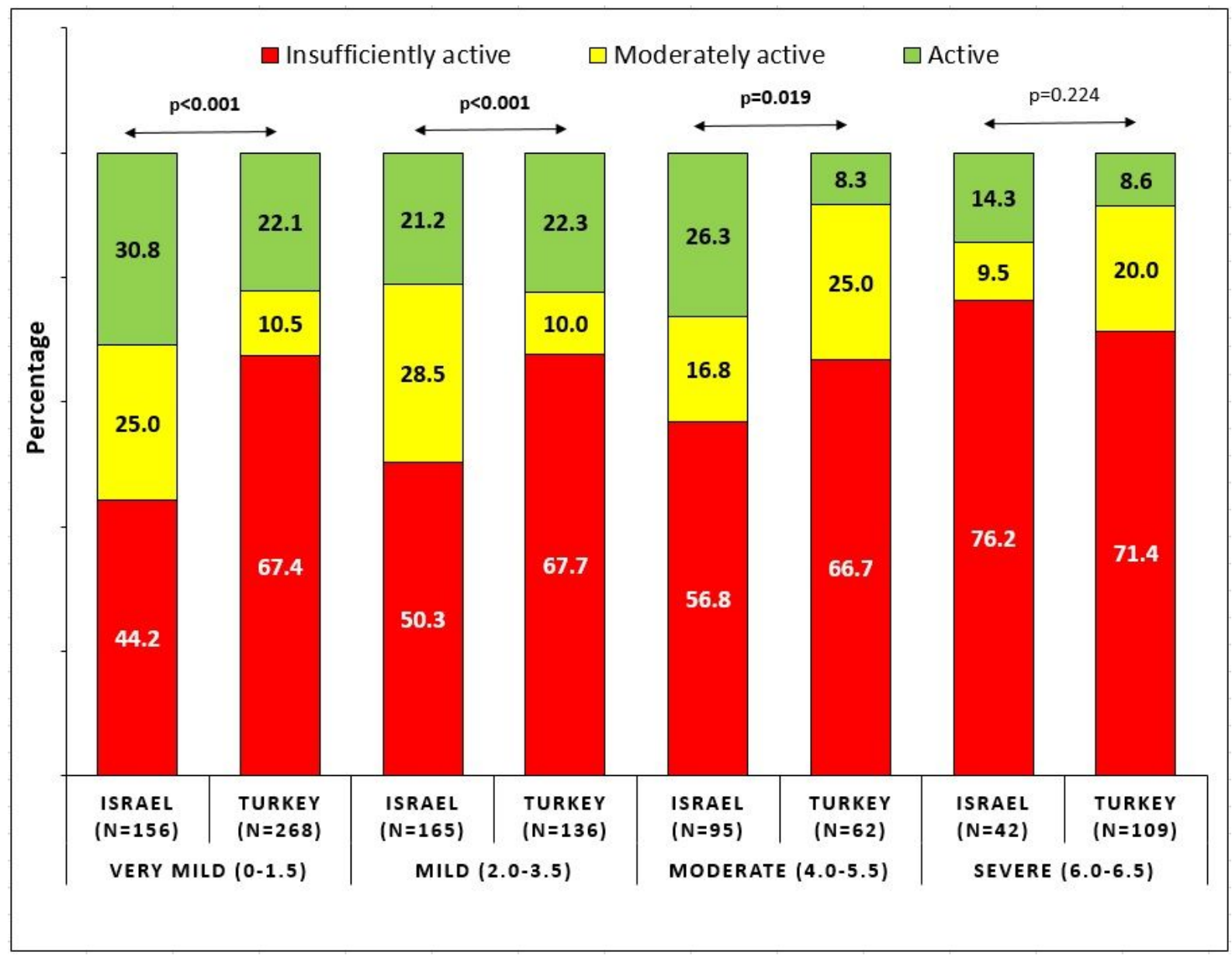

Figure 1

Distribution of physical activity subgroups according to disability (EDSS). 


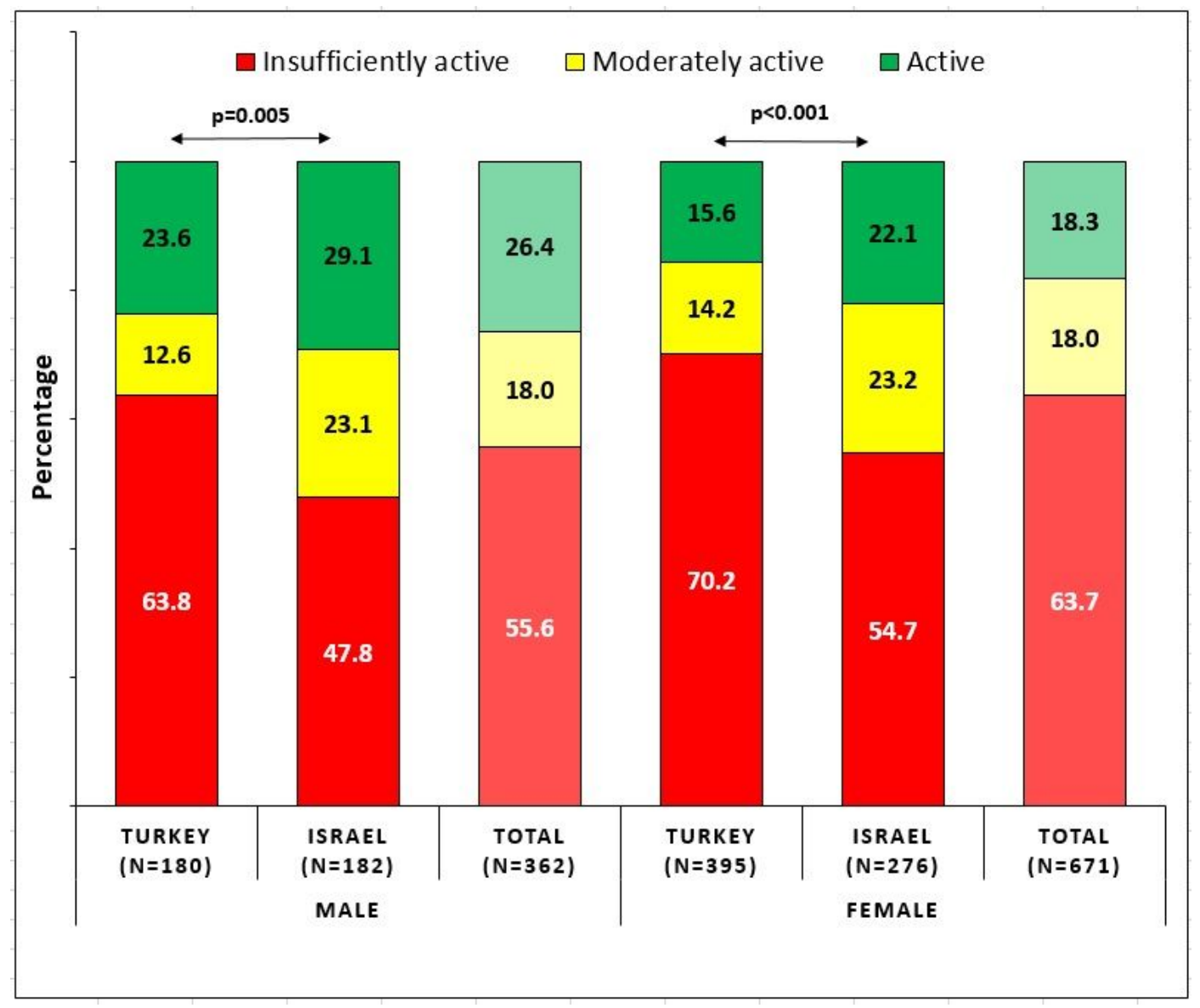

Figure 2

Distribution of physical activity subgroups according to gender.

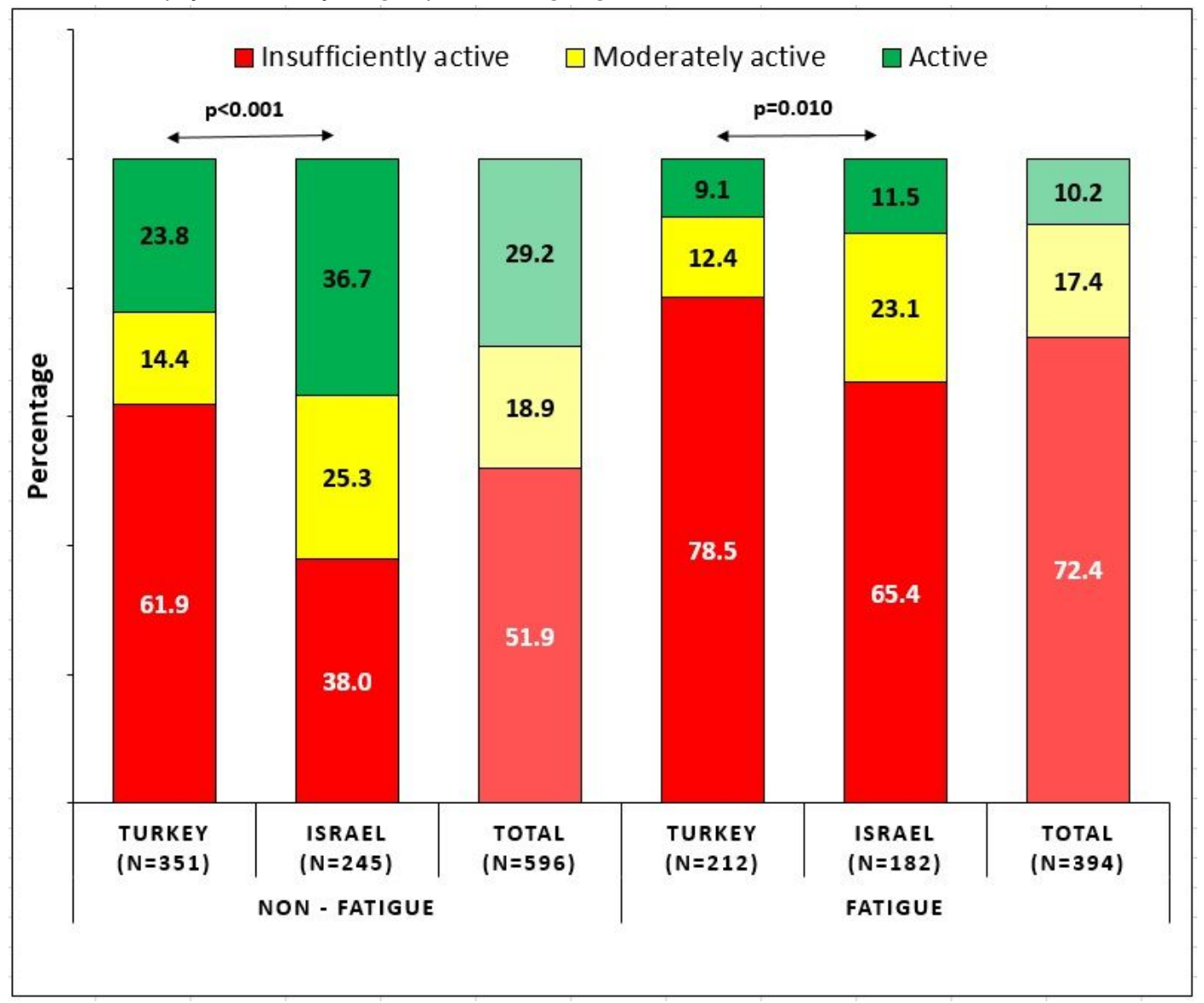


Figure 3

Distribution of physical activity subgroups according to fatigue.

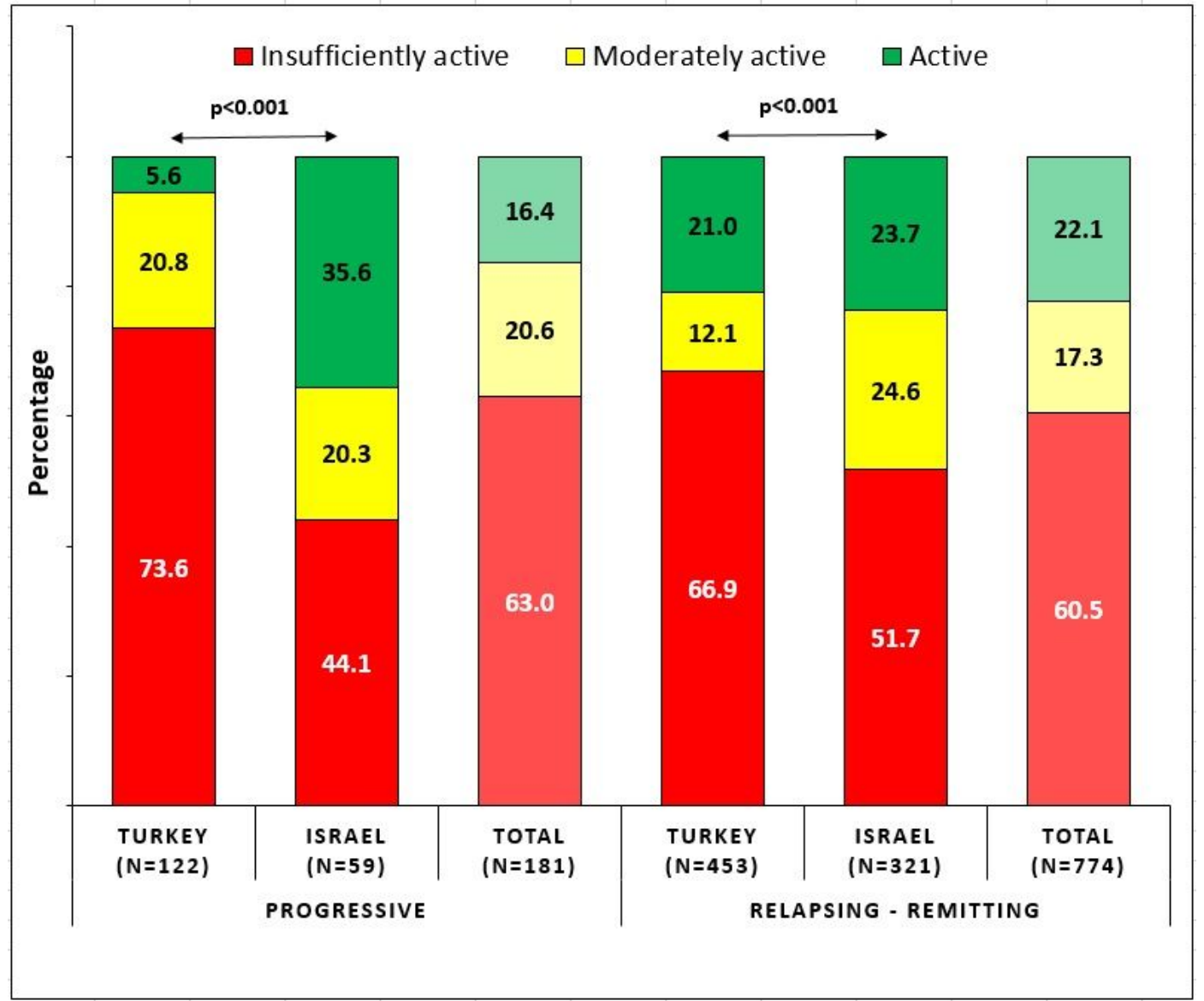

Figure 4

Distribution of physical activity subgroups according to MS type.

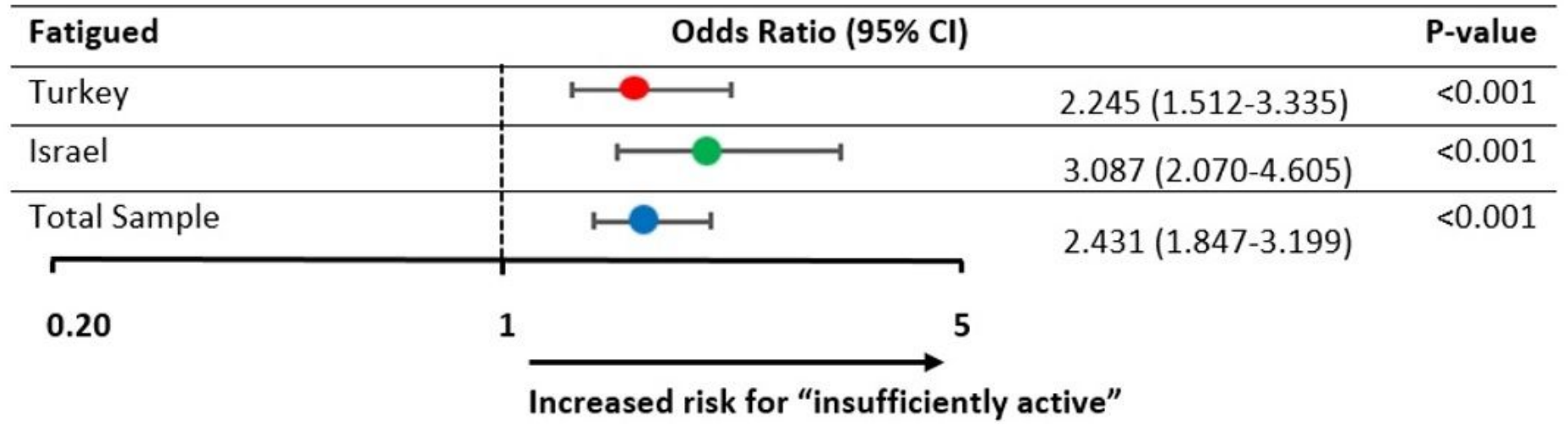

Figure 5

Contribution of fatigue on physical inactivity in terms of odds ratio. 